\title{
Surgical outcomes of Modified supine vs Prone position in Percutaneous Nephrolithotomy
}

\author{
Dr. Balaji A.R ${ }^{1}$, Dr. Lakshminarayan K.R ${ }^{2}$, Dr. Arunkumar Paranjothi ${ }^{3}$ \\ ${ }^{1}$ Professor \& HOD, Department of Urology, Stanley Medical College, Chennai -1. \\ ${ }^{2}$ Junior Resident, Department of Urology, Stanley Medical College, Chennai -1. \\ ${ }^{3}$ Assistant Professor, Department of Urology, Stanley Medical College, Chennai -1.
}

\begin{abstract}
Aim: To compare the surgical outcomes of PCNLs performed using our modified supine position with those performed in the standard prone position

Materials and Methods: 60 patients undergoing Percutaneous nephrolithotomy, at Department of Urology, Government Stanley Medical College \& Hospital, between June 2016 to Jan 2017, were included in the study, and randomized to two groups of 30 each, the former undergoing PCNL in modified supine position and the latter undergoing Prone PCNL. Operative time, radiation time, number of punctures, stone free rate, length of hospital stay, and complications were compared.

Results: There were no differences in number of punctures,stone free or complication rates, between both groups. However, the modified supine group had a lower mean radiation time, operative time and a shorter length of hospital stay.

Conclusion: Modified supine PCNL has significantly lower radiation and operative times, has a shorter length of stay, while being as safe as traditional prone PCNL
\end{abstract}

Keywords: PCNL, Percutaneous Nephrolithotomy, Supine Position, Renal Calculi

\section{Introduction}

Percutaneous nephrolithotomy (PCNL) is the treatment of choice for large and complex renal calculi ${ }^{1}$. Traditionally, PCNL has been performed in the prone position ${ }^{2}$, due to surgeon's familiarity, posterior calyceal puncture, larger surface area for puncture, avoidance of bowel injuries.However, the prone position has anaesthetic disadvantages ${ }^{3}$, especially in overweight and obese patients, or those with pulmonary complications. The modified supine position (The Galdakao-modified Valdivia position) offers several advantages ${ }^{4,5,6}$, reduced impact on the patient's circulatory and ventilatory system, easier monitoring of anaesthesia, simultaneous retrograde access, patient needs to be draped only once and no need of patient reposition. The main characteristic is a slight lateralisation of the Valdivia supine position, with the contralateral leg flexed. The patient is placed in an intermediate supine-lateral position with a 31 Irrigation fluid bottle wrapped in drapes, placed to raise the flank. The ipsilateral leg is extended and the contralateral leg is abducted and flexed, achieving a modified lithotomy position. The aim of the study is to compare surgical outcomes of percutaneous nephrolithotomy done in these two positions.

\section{Materials and Methods}

This is a randomized prospective study, conducted in the Department of Urology, Govt Stanley medical college \& hospital, between June 2016 to Jan 2017. 60 Patients were selected and randomized into two groups, each containing 30 patients. We included all overweight and obese patients (based on BMI) who were candidates for Pcnl, in the study. We excluded patients with prior renal surgeries and with BMI less than 25. Pcnl was done in modified supine position in the first group, and in traditional prone position in the second group. The procedure was done under general anaesthesia. Patients randomized to the prone position group were placed in the lithotomic position, and retrograde ureteric catheterization was performed. All other procedures were completed in the prone position. Patients in the modified supine group were placed in an intermediate supine-lateral position with a tilt of 20-30 degrees, achieved by a 31 Irrigation fluid bottle wrapped in drapes, placed to raise the flank. The ipsilateral leg is extended and the contralateral leg is abducted and flexed, achieving a modified lithotomy position.The ipsilateral arm is supported with a flexed elbow over the chest with the contralateral arm tucked next to the torso with an extended elbow. In both cases, needle puncture was done using fluoroscopy - triangulation technique, following which the tract was dilated using amplatz serial dilators, and the procedure was completed using a Storz 24 Fr Nephroscope and pneumatic lithotripter. DJ Stent and Nephrostomy were placed in all cases. Measured data included Operative time, radiation time, number of punctures, stone free rate, length of hospital stay, and rate of complications. The data was analysed using SPSS software - Chi Square and Fisher's Exact tests. A P Value less than 0.05, was considered statistically significant. 


\section{Results:}

The patient characteristics are tabulated in Table 1 . There was no significant difference between the age and sex distribution and the BMI of the patients in two groups. Operative parameters are shown in Table 2. The modified supine group had a statistically significant $(<0.001)$ shorter operating time $(100+42.8 \mathrm{~min})$ compared to the prone group $(128+47.6 \mathrm{~min})$. The modified supine group also had a shorter radiation exposure of $480 \pm 210$ seconds, which was lesser than $660+298$ seconds of the prone group, and this was also statistically significant (0.005). The modified supine group also had a statistically significant $(0.005)$ shorter duration of stay at the hospital, compared to the prone group. (2.0+1.8 days vs 3.0+2.2 days) Post-operative parameters are shown in Table 3. There were no major complications encountered during the study. There was no statistically significant difference in the minor complication rates between the two groups, such as Transfusion rates, fever, colic and urine leak.

Table 1:

\begin{tabular}{|l|l|l|l|}
\hline Patient Characters & Modified Supine & Prone & p value \\
\hline No of patients & 30 & 30 & \\
\hline Sex & & & \\
\hline Male & 18 & 14 & \\
\hline Female & 12 & 16 & \\
\hline Mean Age & 49.3 & 52.1 & 1 \\
\hline Mean BMI & 32.4 & 30.9 & 0.82 \\
\hline
\end{tabular}

Table 2:

\begin{tabular}{|l|l|l|l|}
\hline Surgical Outcomes & Modified Supine & Prone & p value \\
\hline & & & \\
\hline Operative (in Minutes) & $100 \pm 42.8$ & $128+47.6$ & $<0.001$ \\
\hline Radiation time (in Seconds) & $480 \pm 210$ & $660 \pm 298$ & 0.005 \\
\hline Number of Punctures & & & 0.45 \\
\hline$<3$ & 22 & 25 & \\
\hline$>3$ & 8 & 5 & \\
\hline Stone Free Rates (in \%) & 74.2 & 88.8 & 0.03 \\
\hline Length of Hospital Stay (in days) & $2.0+1.8$ & $3.0+2.2$ & 0.005 \\
\hline
\end{tabular}

Table 3:

\begin{tabular}{|l|l|l|l|}
\hline Complications & Modified Supine & Prone & p value \\
\hline Major & & & \\
\hline Minor & 0 & 0 & 0.91 \\
\hline Transfusions & 12 & 10 & \\
\hline Fever & 3 & 2 & \\
\hline Colic & 5 & 4 & \\
\hline Urine leak & 2 & 3 & \\
\hline
\end{tabular}

\section{Discussion}

PCNL has been traditionally performed in the prone position, with this position still being the most used. In the past decade, however, several variations in patient positioning for PCNL have been proposed. The first described supine position was that of Valdivia in 1998, with a 3-L saline bag below the flank. This position was further modified in 2006, with the Galdakao modified Valdivia position consisting of some rotation to the supine positioning of the contralateral leg in flexion and the ipsilateral leg in extension ${ }^{8}$. The Bart's modified Valdivia position, resulting in a larger surface area for easy access by manipulating the Nephroscope was first described in $2008^{9}$. In 2012, Kumar and associates described 'the Bart's flank-free modified supine position" ${ }^{\text {, }}$. Advantages of the supine position include less patient handling ${ }^{11}$, better drainage of the Amplatz sheath, a combination of antegrade and retrograde approaches, the ability of the surgeon to sit, easier change from spinal or regional to general anaesthesia and higher tolerance, especially in patients with pulmonary or cardiovascular disease. Simultaneous antegrade and retrograde access ${ }^{11}$ which is an advantage of the modified supine position also gives dual access to large stag horn calculi as well as ureteric calculi provides better stone clearance in a single procedure. Furthermore, as the nephroscope enters from below the posterior axillary line, this angle uses gravity to drain the fluid and the residual stone fragments. The modified supine position offers several anaesthetic advantages ${ }^{12}$. Firstly, as the patient is lying supine for the duration of the procedure, there is less pressure placed on their lungs compared to when they are lying prone. This reduces difficulties associated with maintaining stable ventilation of patients while they are prone, particularly obese patients where the abdominal compression can cause decreased venous output. Supine position also allows easier and faster access to the 
airway should the need for reintubation arise. Also, the prone position is associated with increased risk of postoperative visual loss ${ }^{13}$, direct pressure injuries and peripheral nerve damage, particularly to obese patients. Modified supine PCNL avoids all these complications In our study, we found that the modified supine position has a shorter operative time of 20 minutes or more, which can be attributed to the lack of repositioning, preparing and draping the patient, after placing the ureteric catheter. Similar studies by Jones et al. ${ }^{14}$, Liu et al. ${ }^{15}$, show a similar result of shorter operative times with modified supine position Our study also showed a shorter radiation exposure, with modified supine position, which suggests that the time to access and the ease of access in supine position is similar or better than that of prone Pcnl. Our study has also shown that patients with modified supine Pcnl have a shorter duration of stay at the hospital, which can probably be attributed to the lesser anaesthetic morbidity and early recovery associated with supine positioning. Several other studies have shown similar results with supine Pcnl ${ }^{16}$. None of the patients in our study experienced major complications. Complications may occur during or after PCNL and may include extravasation, transfusion, and fever, with an overall complication rate of up to $83 \%$. The rates of major complications, however, including septicaemia, colonic or pleural injury and serious bleeding, have been found to vary from 0 to $4.7 \%$ There were no significant differences between the minor complication rates and the need for transfusion between the two groups. However, some studies have shown higher complication and transfusion rates with supine Pcnl ${ }^{17,18}$, which could be attributed to the surgeon's learning curve and the differing threshold for transfusion at various centres. ${ }^{19}$ Limitations of our study include the small sample size, non-randomization of stone burden, multiple surgeons performing the procedure, and not taking into account the experience and learning curve of individual surgeons.In addition, we did not adjust for stone characteristics such as hardness (stone composition), locations (renal pelvis, upper calyx, and lower calyx) and multiplicity (single or multiple stones)

\section{Conclusion}

We conclude that PCNL in modified supine position is a safe and effective procedure, with similar stone clearance and complication rates as that of traditional prone Pcnl, while having the advantage of lesser radiation exposure to the surgeon and patient, lesser operative time and a shorter hospital stay.

\section{References}

[1]. Turk C. Knoll T, Petrik A, Sarica K, Skolarikos A, Straub M,et al. Guidelines on urolithiasis [Internet] Arnhem (NL): European Aossciation of Urology; c2015 [cited 2015 May 23].

[2]. Valdivia JG, Scarpa RM, Duvdevani M, Gross AJ, Nadler RB,Nutahara K, et al. Supine versus prone position during percutaneous nephrolithotomy: a report from the clinical research office of the endourological society percutaneous nephrolithotomy global study. J Endourol 2011;25:1619-25.

[3]. de la Rosette JJ, Tsakiris P, Ferrandino MN, et al. Beyond prone position in percutaneous nephrolithotomy: A comprehensive review. Eur Urol 2008;54:1262-1269

[4]. Manohar T, Jain P, Desai M. Supine percutaneous nephrolithotomy: Effective approach to high-risk and morbidly obese patients. J Endourol 2007;21:44-49.

[5]. Yamaguchi A, Skolarikos A, Buchholz NP, et al. Operating times and bleeding complications in percutaneous nephrolithotomy: A comparison of tract dilation methods in 5,537 patients in the Clinical Research Office of the Endourological Society Percutaneous Nephrolithotomy Global Study. J Endourol 2011;25:933-939.

[6]. Steele D, Marshall V. Percutaneous nephrolithotomy in the supine position a neglected approach? J Endourol 2007;21:1433-1437.

[7]. Valdivia Uria JG, Valle Gerhold J, Lopez Lopez JA, et al. Technique and complications of percutaneous nephroscopy: experience with 557 patients in the supine position. J Urol 1998;160:1975-1978.

[8]. Ibarluzea G, Scoffone CM, Cracco CM, et al. Supine Valdivia and modified lithotomy position for simultaneous anterograde and retrograde endourological access. BJU Int 2007;100: 233-236.

[9]. Papatsoris AG, Zaman F, Panah A, et al. Simultaneous anterograde and retrograde endourologic access: 'The Barts technique'. J Endourol 2008;22:2665-2666.

[10]. Kumar P, Bach C, Kachrillas S, et al. Supine percutaneous nephrolithotomy (PCNL): 'in vogue' but in which position? BJU Int 2012;110(11 Pt C):E1018-1021.

[11]. McCahy P, Rzetelski-West K, Gleeson J. Complete stone clearance using a modified supine position: initial experience and comparison with prone percutaneous nephrolithotomy. J Endourol 2013;27:705-9.

[12]. Atkinson CJ, Turney BW, Noble JG, Reynard JM, Stoneham MD. Supine vs prone percutaneous nephrolithotomy: an anaesthetist's view. BJU Int 2011;108:306-8

[13]. Agah M, Ghasemi M, Roodneshin F, Radpay B, Moradian S. Prone position in percutaneous nephrolithotomy and postoperative visual loss. Urol J 2011;8:191-6.

[14]. Jones MN, Ranasinghe W, Cetti R, Newell B, Chu K, Harper M, Kourambas J, McCahy P. Modified supine versus prone percutaneous nephrolithotomy: Surgical outcomes from a tertiary teaching hospital. Investig Clin Urol. 2016 Jul;57(4):268-273.

[15]. Liu L, Zheng S, Xu Y, Wei Q. Systematic review and meta analysis of percutaneous nephrolithotomy for patients in the supine versus prone position. J Endourol 2010;24:1941-6

[16]. Mazzucchi E, Vicentini FC, Marchini GS, Danilovic A, Brito AH, Srougi M. Percutaneous nephrolithotomy in obese patients: comparison between the prone and total supine position. J Endourol 2012;26:1437-42.

[17]. Scoffone CM, Cracco CM, Cossu M, Grande S, Poggio M, Scarpa RM. Endoscopic combined intrarenal surgery in Galdakaomodified supine Valdivia position: a new standard for percutaneous nephrolithotomy? Eur Urol 2008;54:1393-403

[18]. De Sio M, Autorino R, Quarto G, Calabrò F, Damiano R, Giugliano F, et al. Modified supine versus prone position in

[19]. percutaneous nephrolithotomy for renal stones treatable with a single percutaneous access: a prospective randomized trial. Eur Urol 2008;54:196-202.

[20]. Falahatkar S, Moghaddam AA, Salehi M, et al. Complete supine percutaneous nephrolithotripsy comparison with the prone standard technique. J Endourol 2008; 22:2513-2517. 